\title{
Knowledge of cervical cancer pathology of high school students in San Carlos, Costa Rica
}

\author{
Lauren M. Carlson ${ }^{1} \&$ Sam Gonzalez ${ }^{2}$ \\ 1. St. Olaf College, Northfield, MN, USA; carlsonl@stolaf.edu \\ 2. Macalester College, St. Paul, MN, USA; scarlos1790@gmail.com
}

Received 20-III-2014. Corrected 20-IV-2014. Accepted 26-V-2014.

\begin{abstract}
In Costa Rica, cervical cancer is the second most common female cancer, despite accessibility of screening through the universal health care system. There is little understanding of knowledge levels of the adolescent population on cervical cancer, although this population is the most exposed to risk factors. This study sought to learn about male and female adolescent knowledge of preventative methods, infection acquisition, clinical manifestations and medical services. A total of 533 students from grades 7-12 from five public high schools in the rural San Carlos region participated in the study from March through April 2012. Students were found to lack knowledge, as only $30.8 \%$ of students stated that they knew what cervical cancer is. Additionally, a connection was lacking between cervical cancer concepts, as for example $75.2 \%$ of students had heard of Human Papiloma Virus, but only 33.9\% of those students knew that HPV is related to cervical cancer. Age had a positive relationship with knowledge of main concepts $(\mathrm{p} \leq 0.001)$. More women than men had heard of cervical cancer and the Papanicolaou $(\mathrm{p}=0.025, \mathrm{p} \leq 0.0001)$, but otherwise no significant difference in mean response between genders was found. Students were found to have a limited awareness of the educational cervical cancer campaign (7.7\% of the student population) and the ability to go alone to the doctor to receive medical attention $(30.6 \%$ of students). Additionally, the public education system does not require cervical cancer to be included in the present curriculum. Hence, as students lack education on prevention and risk factors, the majority of prevention responsibility falls only on the universal health care system to regularly perform Papanicolaou exams to detect pre-cancerous or cancerous changes. The findings indicated the importance of including cervical cancer in the sexual education curriculum of the public education system in Costa Rica to educate the at-risk population of preventative methods, infection development, clinical manifestations and medical services in order to lower the presence of cervical cancer. Rev. Biol. Trop. 62 (3): 877-886. Epub 2014 September 01.
\end{abstract}

Key words: adolescents, cervical cancer, Costa Rica, Papanicolaou, sex education.

In order to prevent cervical cancer one should limit exposure to Human Papilloma Virus, especially by avoiding the main risk factors: an early onset of sexual activity and an elevated number of sexual partners (American Cancer Society, 2011). Additional risk factors include sexually transmitted diseases, smoking, obesity, contraceptive medications and unprotected sexual intercourse (American Cancer Society, 2011).

Cervical cancer develops due to gradual changes in the cervix after persistent, repeated HPV infections (Feldman, Sirovich, \&
Goodman, 2011). About $90 \%$ of the infections naturally clear, yet to avoid HPV exposure or to receive a HPV vaccination is highly recommended (Maine, Hurlburt, \& Greeson, 2011). The Papanicolaou (Pap smear) is the most common screening test, or method to detect treatable pre-cancerous formations (Feldman et al., 2011). Screening is recommended every other year for sexually active women at least 20yrs old (Feldman et al., 2011).

Symptoms of cervical cancer, particularly abnormal vaginal bleeding and pain during sexual intercourse, generally arise in the latest 
stages of the disease (American Cancer Society, 2011). Development from localized to metastasized cancer typically takes $10-15 \mathrm{yrs}$ (RHO Cervical Cancer, 2009). The survival rate for localized cancer is $90 \%$, yet only $16.5 \%$ for metastasized cancer (American Cancer Society, 2011). This emphasizes the importance of detecting cervical cancer early through the Papanicolaou before symptoms arise.

Cervical cancer is the second most common cancer facing Costa Rican women (Aguado, Beauvais, Byrne, \& Gacic-Dobo, 2010). Every year, an estimated 403 women are positively diagnosed and 158 die due to cervical cancer, in a population of over 2 million (Aguado et al., 2010; Instituto Nacional de Estadística y Censo [INEC], 2011). Screening methods are available for this preventable disease through Costa Rica's universal health care system (Kivistik, Lang, Baili, Antitila, \& Veerus, 2011). However, only an estimated $44.8 \%$ of Costa Rican women are yearly screened and $17 \%$ of women over 65yrs-old have never received a Pap smear (Aguado et al., 2010). Meanwhile, 52\% of the sexually active Costa Rican population faced the onset of sexual activity between 14 and $17 \mathrm{yrs}$ of age, putting them at a greater risk of contracting cervical cancer (Picado, 2007).

Few studies have investigated the level of cervical cancer knowledge of males, teenagers or Latinos. A South African study focused on the knowledge of males of cervical cancer, found an extremely limited level of knowledge towards the disease and risk factors (Maree, Wright, \& Makua, 2011). In another study, Nigerian women did not utilize screening exams, as they lacked knowledge of the disease and screening accessibility (Nwankwo, Aniebue, Aquwa, Anarado, \& Aqunwah, 2011). Another South African study on the female population found basic preventative education should be given, in a manner appropriate to the cultural context (Francis et al., 2011). In socially-deprived areas of the United States acceptance of the Papanicolaou exam is lacking and these women not only were found to have a limited knowledge, but negative attitudes towards screening (Logan \& Mcifatrick, 2011).
The "Caja Costarricense de Seguro Social" (CCSS), the universal health care system of Costa Rica, works to prevent cervical cancer through education and conducting the Papanicolaou (A. Muñoz, personal communication, April 16, 2012). One week during each October or November is dedicated to the "Semana de Salud" ("Health Week"). During this time, stands are placed outside the EBAIS, the local public clinics, each with different health themes. One stand is dedicated to cervical cancer and is geared towards teenagers, as they are the most vulnerable population since they are less likely to use condoms. They also work to regularly screen the female population.

Each adolescent that comes to the clinic receives a "risk classification." When a patient indicates they are sexually active, the doctor speaks with the patient without their parents. In addition to receiving a discussion about reducing risk factors and receiving free contraceptives, females are advised to schedule a Pap smear for another day when they can come alone.

The objectives of this study were to measure: a) the level of knowledge of the adolescent population concerning: preventative measures, infection development, metastasis and available medical services; b) the level of knowledge related to age, gender and school type; c) other potential barriers inhibiting women from receiving screening tests.

\section{MATERIALS AND METHODS}

Study area: The study took place in Costa Rica in the province of Alajuela, within the towns of Aguas Zarcas, Río Cuarto, La Palmera and Venecia. Aguas Zarcas $\left(10^{\circ} 20^{\prime} \mathrm{N}\right.$ $\left.84^{\circ} 26^{\prime} \mathrm{W}\right)$ and Venecia $\left(10^{\circ} 22^{\prime} 0^{\prime \prime} \mathrm{N}-84^{\circ} 17^{\prime} 0^{\prime \prime}\right.$ W) are located $15 \mathrm{~km}$ and $28 \mathrm{~km}$, respectively, from Ciudad Quesada, the largest city of the San Carlos region (Souza, 2011). Aguas Zarcas is $97 \mathrm{~km}$ North of San José, the capital of Costa Rica (Souza, 2011). Aguas Zarcas has an estimated population of 13651 residents (INEC, 2011). There are three high schools in the Aguas Zarcas district, including one in La 
Palmera. Venecia has an estimated population of 7394 residents (INEC, 2011). There are four high schools within the Venecia district, including one school in Río Cuarto.

Study population: The study included public high school students from five schools within the Venecia and Aguas Zarcas school districts. Only students from grades 7-12 who consented to research were eligible to participate. High school sizes ranged from approximately 200 to 1200 students (Table 1). A total of 533 students participated. The technical high schools ranged from grades 7-12, while academic high schools ranged from grades 7-11.

Procedure/Creating questionnaire: First, we created a questionnaire to analyze the level of knowledge of cervical cancer of male and female adolescents. To test for a basic level of understanding, we included initial questions pertaining to cervix identification, mortality and symptoms, as well as stating whether or not they know what cervical cancer is. Additionally, we added a series of questions about risk factors, HPV and infection acquisition, to measure the understanding of students of cervical cancer prevention.

We asked students to state whether they had heard of an educational cervical cancer

TABLE 1

Age and total number of students participating in the study for each age sampled. San Carlos, Costa Rica. March-April 2012

\begin{tabular}{cc} 
Age (years) & Number of Participants \\
12 & 44 \\
13 & 82 \\
14 & 73 \\
15 & 76 \\
16 & 58 \\
17 & 56 \\
18 & 102 \\
19 & 26 \\
20 & 9 \\
21 & 3 \\
22 & 1 \\
\hline
\end{tabular}

campaign in their community or not, and to assess the level of its presence. We also included questions to measure the knowledge of teenagers about the medical services available, such as the Papanicolaou and whether unaccompanied doctor visits were possible. The final question asked students to identify potential barriers to going alone to the doctor.

Receiving approval: Before beginning research, we received approval from the St. Olaf Institutional Review Board. Then we received approval from the: a) regional director, Lic. Oscar Oviedo Valerio, at the Ministry of Education in Ciudad Quesada; b) district supervisor of Venecia, Rodolfo González, to receive permission to work within the Venecia school district; c) Rodolfo Salas, the district supervisor of Agua Zarcas, and d) high school principals.

Initial field research: We randomly chose classes to start distributing parental consent forms. We gave each class a brief explanation of the study, along with instructions to have their parent/guardian sign the consent form that night. We recorded each class section visited and their class schedule for the next day. The following day, we returned to the same class sections to distribute a student consent form to minors that returned the signed parental consent form and to those at least $18 \mathrm{yrs}$ old. We then administered the questionnaire to the students with both completed forms. We transferred the questionnaire results onto an electronic data sheet. We returned a third day to the same class sections to distribute questionnaires to any additional students who had brought the signed parental consent form. We repeated this process with every class section possible.

For most questions we used a condensed Likert scale with 0 and $1 ; 0=$ an incorrect or negative response and $1=$ a correct or positive response. We constructed frequency histograms of median answers with Microsoft Excel. Relationships between several dependent variables from questionnaire responses 
with age of respondent (independent variable) were estimated with simple linear parametric regression. Dependencies of responses between pairs of certain questions were estimated with contingency tables. Differences between mean responses of questions grouped by several participant characteristics were carried out with one-way, parametric ANOVA. Homogeneity of variance was tested before applying parametric ANOVA. Statistical procedures followed Sokal and Rohlf (1995). Statistical tests were run with Statgraphics Centurion XVI (Statpoint Technologies, Inc., 2011)

Return to the field: Following data analysis, we returned to San Carlos to discuss the findings and leave copies of the final paper with the medical doctor of EBAIS 2 of Venecia, the regional director in Ciudad Quesada, as well as the district supervisors, principals and interested teachers of each high school. We additionally left the answers to the questionnaires at each high school with enough copies for each teacher and class section, so the students could receive the correct information.

\section{RESULTS}

Participants: A total of 533 students completed the questionnaire from the five high schools studied. Participants ranged from 12-22yrs old and from grades 7-12 (Table 1). A total of 315 respondents were identified as females, and 216 identified as males.

The individual return rates of each school varied from $13.8 \%$ to $39.5 \%$. The overall return rate was $27.5 \%$. The technical schools had an overall return rate of $14.3 \%$, while the academic schools had an overall return rate of $32.0 \%$, excluding the Colegio Técnico de Aguas Zarcas, as not all of the classes were reached.

Preventative measures: Only $7.7 \%$ of students had heard of the presence of an educational cervical cancer campaign in their community. A total of $30.8 \%$ of students stated they knew what cervical cancer is, with the mean response for females $(\bar{x}=0.35)$ greater than for males $(\bar{x}=0.25)(\mathrm{F}=5.04$, d.f. $=1, \mathrm{p}=0.025$; $\mathrm{n}=529)$. We found that $41.5 \%$ of the students knew cervical cancer is preventable. In identifying the two key risk factors, $30.8 \%$ of students identified an early onset of sexual activity and $37.1 \%$ identified an elevated number of sexual partners. A total of $92.1 \%$ of students identified at least one correct risk factor.

A total of $67.9 \%$ of students had heard of the Papanicolaou (Table 2). There was a strong positive relationship between age and likelihood of hearing of the PAP ( $\mathrm{F}=27.1$, d.f. $=1$, $\mathrm{p} \leq 0.0001, \mathrm{r}^{2}=4.88 \% ; \mathrm{n}=528$, Table 3, Fig. 1). Additionally, mean female response $(\bar{x}=0.73)$

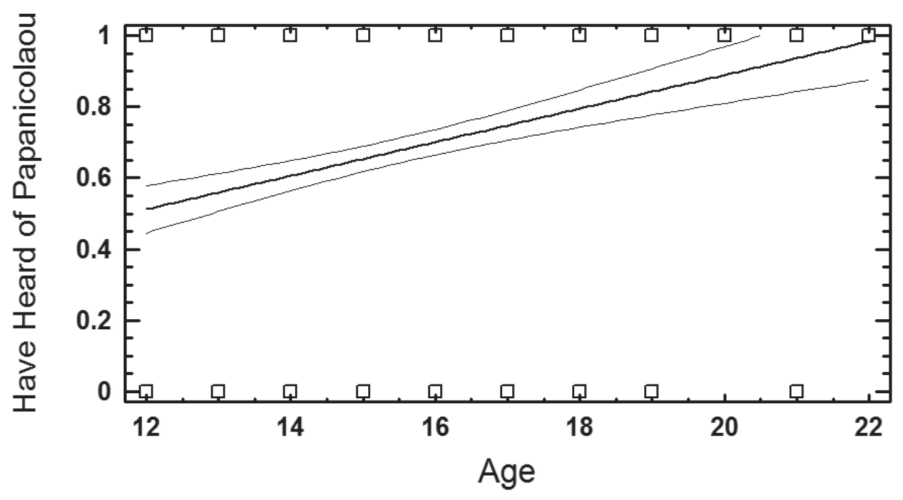

Fig. 1. Relationship between student age (12-22 years old) and response when asked, "Have you heard of the Papanicolaou (PAP)?" Values of " 0 " and "1" represent responses of "no" and "yes", respectively. Equation is: "Heard of PAP?"=$0.0544+0.0472 *$ Age. Concave lines are 95\% confidence intervals of the estimated line. San Carlos, Costa Rica. MarchApril 2012. 
TABLE 2

Questionnaire responses and the percentage of students who gave each response.

San Carlos, Costa Rica. March-April 2012

Response

Percentage of Responses (\%)

\section{Prevention \& Risk Factors}

Had heard of an educational cervical cancer campaign

Stated cervical cancer is preventable

Identified an early onset of sexual activity as a risk factor

Identified a high number of sexual partners as a risk factor

Had heard of the Papanicolaou

Infection

Had heard of the Human Papilloma Virus

Stated cervical cancer is acquired only through an infection

Had heard of HPV and stated it has an association with cervical cancer 33.9

\section{Metastasis}

Identified vaginal bleeding as a symptom

69.4

Identified pain during sexual intercourse as a symptom

48.2

Stated cervical cancer is fatal

\section{Additional Information}

Correctly identified the cervix

\section{Contributory Facts}

Stated adolescents can go to the doctor alone

was greater than male response $(\bar{x}=0.60)$ $(\mathrm{F}=9.37$, d.f. $=1, \mathrm{p}=0.0023 ; \mathrm{n}=528)$. There also was a positive dependency between knowing cervical cancer is preventable and having heard of the Papanicolaou $\left(X^{2}=9.22\right.$; d.f. $=1$; $\mathrm{p}=0.0024$ ).

Infection development: We found $75.2 \%$ of the students had heard of Human Papilloma Virus (Table 2). A strong positive relationship existed between age and likelihood of hearing of HPV ( $\mathrm{F}=61.9$, d.f. $=1, \mathrm{p}<0.0001, \mathrm{r}^{2}=10.5 \%$; $\mathrm{n}=528$, Fig. 2). There was a positive dependency between having heard or not about cervical cancer, with having heard or not about HPV $\left(X^{2}=5.267\right.$; d.f. $\left.=1 ; p=0.0217\right)$. Yet, of the students who stated they knew what cervical cancer is and had heard of HPV, only $40.3 \%$ stated HPV has a relation to cervical cancer.

Clinical manifestations: In recognizing cervical cancer symptoms, $69.4 \%$ of students identified vaginal bleeding and $48.2 \%$ identified pain during sexual intercourse (Table 2).
There was also a positive relationship between age and likelihood of answering a correct symptom $\left(\mathrm{F}=5.18\right.$, d.f. $=1, \mathrm{p}=0.0232, \mathrm{r}^{2}=0.97 \%$; $\mathrm{n}=528)$.

Additional information: Overall, 39.4\% of students correctly identified the cervix from an image of the female reproductive system (Table 2). There was a strong positive relationship between age and responding correctly $\left(\mathrm{F}=28.1\right.$, d.f. $\left.=1, \mathrm{p}<0.0001, \mathrm{r}^{2}=5.06 ; \mathrm{n}=528\right)$.

Medical services: We found $30.6 \%$ of students knew adolescents can go alone to the clinic for medical services (Table 2). Yet, 51\% of students responded they would go alone to the clinic (Table 2). There was a strong positive relationship between age and the willingness to go alone $(\mathrm{F}=74.8$, d.f. $=1, \mathrm{p} \leq 0.0001$, $\mathrm{r}^{2}=12.53 ; \mathrm{n}=522$, Fig. 3). Additionally, mean male response $(\bar{x}=0.59)$ was greater than mean female response $(\bar{x}=0.45) \quad(\mathrm{F}=10.96$, d.f. $=1$, $\mathrm{p}=0.0010 ; \mathrm{n}=529)$. 
TABLE 3

Question, F-Value, Degrees of Freedom, P-Value and $\mathrm{R}^{2}$ of each significant regression analysis.

San Carlos, Costa Rica. March-April 2012

\begin{tabular}{|c|c|c|c|c|c|}
\hline Question & F-Value & df & $\mathrm{n}$ & P-Value & $\mathrm{R}^{2}(\%)$ \\
\hline \multicolumn{6}{|l|}{ Preventative Measures } \\
\hline Have you heard of the Papanicolaou (PAP)? & 27.10 & 1 & 528 & $<0.0001$ & 4.88 \\
\hline \multicolumn{6}{|l|}{ Infection Development } \\
\hline Have you heard of HPV? & 61.88 & 1 & 528 & $<0.0001$ & 10.49 \\
\hline \multicolumn{6}{|l|}{ Metastasis } \\
\hline Identify the symptoms of cervical cancer & 5.18 & 1 & 528 & $=0.0232$ & 0.97 \\
\hline \multicolumn{6}{|l|}{ Additional Information } \\
\hline Identify the cervix & 28.14 & 1 & 528 & $<0.0001$ & 5.06 \\
\hline \multicolumn{6}{|l|}{ Contributory Facts } \\
\hline $\begin{array}{l}\text { Can an adolescent go without their parent/guardian to the } \\
\text { clinic for medical attention? }\end{array}$ & 32.36 & 1 & 528 & $<0.0001$ & 5.78 \\
\hline $\begin{array}{l}\text { Would you go to the clinic without your parent/guardian } \\
\text { for medical attention? }\end{array}$ & 74.78 & 1 & 522 & $<0.0001$ & 12.53 \\
\hline
\end{tabular}

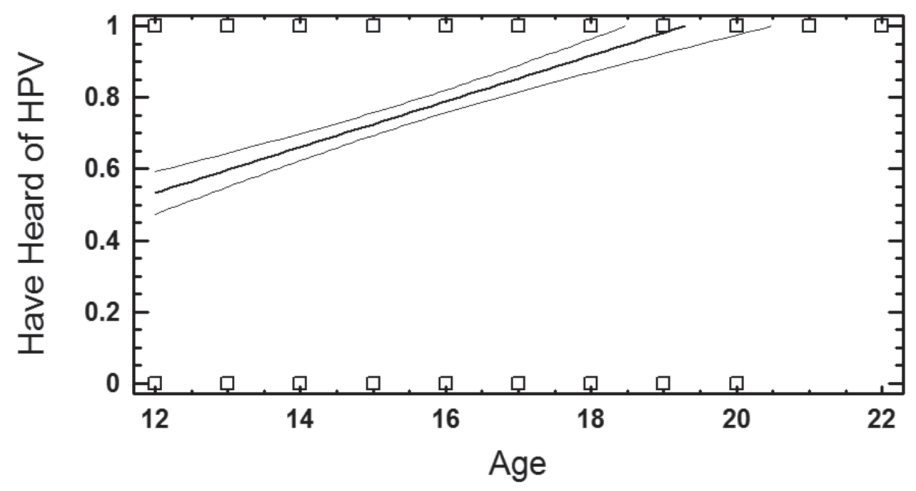

Fig. 2. Relationship between student age (12-22yrs old) and response when asked, "Have you heard of the Human Papilloma Virus?" Values of "0" and "1" represent responses of "no" and "yes", respectively. Equation is: "Heard of HPV?"=$0.2353+0.0640 *$ Age. Concave lines are $95 \%$ confidence intervals of the estimated line. San Carlos, Costa Rica. March-April 2012.

The most common reasoning for unwillingness to go alone to the doctor consisted of "fear of parental punishment", "embarrassment of sharing personal information with parents" and "fear of the doctor", while the two least common reasons were "embarrassment with friends" and "embarrassment with boyfriend/ girlfriend". Mean female response $(\bar{x}=0.30)$ was greater than male response $(\bar{x}=0.13)$ for choosing "fear of the doctor" $(\mathrm{F}=20.1$, d.f. $=1$, $\mathrm{p} \leq 0.0001 ; \mathrm{n}=529$ ).

\section{DISCUSSION}

A disconnection existed between the knowledge of adolescents with various cervical cancer concepts. For example, nearly all of the students identified at least one risk factor, but less than half stated cervical cancer is preventable. Hence, the majority of students did not understand that avoiding risk factors prevents the acquisition of the disease. Additionally, only less than half of the students who knew what cervical cancer is and had heard 


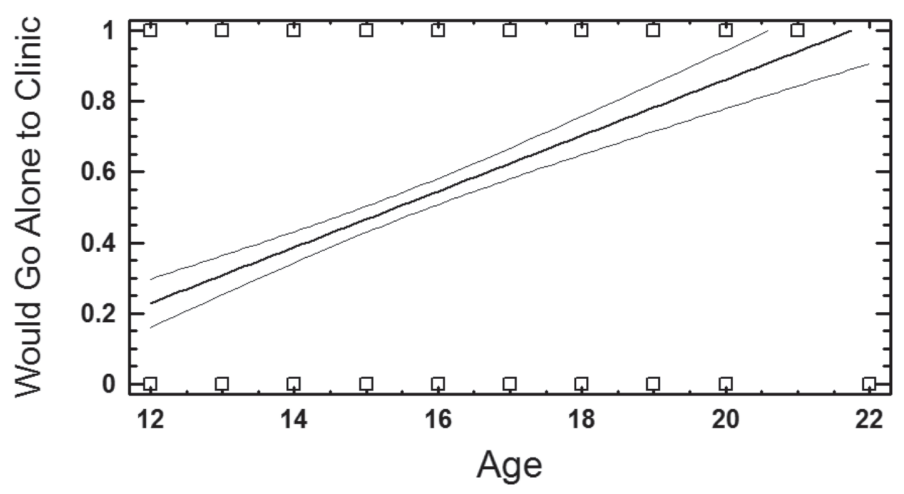

Fig. 3. Relationship between student age (12-22 years old) and response when asked if they personally would be willing to go to the clinic alone to receive medical attention. Values of " 0 " and "1" represent responses of "no" and "yes", respectively. Equation is: "Would Go Alone to Clinic?" $=-0.7207+0.0791 *$ Age. Concave lines are $95 \%$ confidence intervals of the estimated line. San Carlos, Costa Rica. March-April 2012.

of HPV, also stated that HPV has a relation to cervical cancer.

The questionnaire included two openended questions to allow for students to demonstrate their level of knowledge of cervical cancer and the Papanicolaou. While less than one-third of students stated they knew what cervical cancer is, when asked to define the disease, the majority of responses consisted of "cancer of the cervix" and possibly included information describing it as sexually transmitted or a female disease. This showed the students were lacking a depth of knowledge. Only three students were able to connect the Papanicolaou with cervical cancer and only five students mentioned prevention. This demonstrated a lack of understanding between connecting cervical cancer topics.

According to a study conducted in the United Kingdom, women living in sociallydeprived areas also had a limited knowledge of cervical cancer risks and prevention strategies (Logan \& Mcifatrick, 2011). Researchers of a similar study in South Africa, where cervical cancer is also the second-leading cause of death among women, stated prevention methods and materials are necessary to inform women about HPV, cervical cancer, screening and discussing the topic with children (Francis et al., 2011).

With a few principal questions, a positive correlation existed between age and knowledge of cervical cancer and medical services, specifically: identifying the cervix, identifying symptoms, hearing of the Papanicolaou, hearing of HPV and knowing adolescents can go alone to the doctor. A study in Nigeria found only $15 \%$ of participants knew of the availability of cervical cancer screening, which had a positive correlation with the level of education attainment (Nwankwo et al., 2011). The number of students in our study that knew they could go to the doctor alone, which had a positive correlation with the level of education attainment, was nearly double the amount in the Nigerian study.

As students aged, they were more likely to be willing to go alone to the doctor. With age, the students likely feel more independent. Also as they aged, the reasoning of students for not going to the clinic alone changed from "fear of parental discipline" to "embarrassment of sharing personal information with their parents". The older the student, the more likely they were to have been sexually active and, therefore, could be associated with a reason to feel embarrassed (Picado, 2007).

Women were more likely to state they knew what cervical cancer is or have heard of the Papanicolaou. Yet, there was no significant correlation between gender and knowledge of HPV or cervical cancer risk factors. A study conducted on South African men found men lack knowledge of cervical cancer, as no 
participants mentioned the importance of HPV and only a few knew having multiple sexual partners was a risk factor (Maree et al., 2011). In contrast, about three-fourths of both Costa Rican male and female students stated they had heard of HPV, with no significant difference between genders. Maree et al. (2011) stated men need to be informed of cervical cancer as they can help protect women from risk factors and encourage screening. Although Costa Rican men had stated they had heard of HPV, few could relate the virus to cervical cancer, showing an overall lack of connection between these concepts.

Although Costa Rican females were slightly more informed of cervical cancer and the Papanicolaou, males were more likely to be willing to go alone to visit the doctor. At the same time, females were more likely to be deterred by their "fear of the doctor". Hence, males could help support females in receiving the screening exam.

Regarding responsibility for cervical cancer prevention, in order to prevent cervical cancer, one can limit exposure to HPV infection through limiting risk factors and routinely receiving a Papanicolaou in order to prevent pre-cancerous infections from forming cancer (Feldman et al., 2011). Ideally, one would receive a HPV vaccination, but this is not covered through the CCSS, which means it is unrealistic for much of the population to receive. (A. Muñoz, personal Communication, April 16, 2012). In order to limit risk factors, education of risk factors needs to reach the population before they become sexually active, as this exposes them to HPV (American Cancer Society, 2011).

Unfortunately, the current, formal, required curriculum by the MEP does not require information on cervical cancer to be included. Fewer than one-third of students both know they can go alone and are willing to go alone. This shows few students are going alone to the clinic and, therefore, are probably less likely to receive information on sexual education from doctors. Therefore, few students receive information from educational campaigns, school or the clinic, so the majority likely isn't receiving the key preventative measure, which is education.

Hence, the majority of the responsibility of cervical cancer prevention falls upon CCSS intervention after the onset of sexual activity and potential exposure to HPV, by providing Papanicolaou exams in order to detect any pre-cancerous or cancerous lesions. There are also potential barriers preventing women from receiving routine Papanicolaou, as only $44.8 \%$ of Costa Rican women are yearly screened (Aguado et al., 2010). A study conducted in the United States found distrust in the healthcare system was negatively correlated with utilization of cervical cancer screening (Tse-Chuan, Matthews, \& Hillemeier, 2011). Although we did not measure health care system distrust, nearly half of students with reasoning for not going alone to the clinic chose, "fear of the doctor". Hence, this could prevent utilizing the accessible screening exam. Therefore, it is even more crucial to educate the population on risk factors.

As regards intervention strategies, this study showed students were lacking information not only on cervical cancer. High school students would benefit from a specific sexual education course. Otherwise, cervical cancer could be added to the already required curriculum pertaining to sexually transmitted diseases. Currently health discussions are given 2-3 times a year by the CCSS to the student population, but this is dependent on funding. Hence, we stress the importance of keeping these health discussions a priority of the community.

Less than half of the students who completed the questionnaires were willing to go to the doctor alone, nearly one quarter of these students because of "embarrassment of sharing personal information with their parents". Hence, it is also possible that students accompanied by their parents would avoid correctly filling out the risk classification sheet in the case they are fearful of the response of their parents. We think it would be ideal for the CCSS to offer yearly physicals for students at 
the high schools so students would feel more comfortable going alone to visit the doctor.

The limitations or obstacles we faced included a low return rate of parental consent forms, from forgetfulness or unwillingness of students and/or parents. When there were only a few students of a classroom with a signed permission slip, it was more likely they would choose not to participate. In the Colegio Técnico de Venecia, the principal distributed a consent form, containing incorrect information, to students before we went to the high school. Therefore, students with these consent forms could not participate either.

In a few classes, teachers would discuss cervical cancer after their students asked questions about the study. Students also discussed the questions between themselves, during and after taking the questionnaire. This could distort the data, as the discussions were only prompted by our presence.

With regard to future research, this study created new questions concerning the barriers of cervical cancer screening. As in the one EBAIS we visited, the male doctor had a significantly lower number of Papanicolaou exams administered in 2011 than the female doctor; it would be important to analyze the mean number of Pap smears administered between male and female providers. Alongside, it would be beneficial to compare women's comfort levels in receiving the exam by doctors of each gender.

Three formal cervical cancer education methods exist for adolescents in the San Carlos region: Semana de Salud once a year, discussions by medical doctors in the high schools and visits with the doctor. The trend that males were more likely to hear of an educational cervical cancer campaign in their community lacks an explanation and would be a source for future study. Additionally, it is important to know which of these education types are most effective, in order to ensure teenagers are receiving the information in an appropriate manner.

\section{ACKNOWLEDGMENTS}

We would like to thank our advisors, Diana and Freddy Ulate, who helped us design and carry out a realistic study that is beneficial to Costa Rica. Additionally, we would like to acknowledge the support of ACM staff, especially Michael McCoy and Chris Vaughan, who helped us along every step of the research process. Thanks also go to the student participants, as without their willingness and initiative we would not have a study. The warm welcome and above and beyond patience of the superintendent, directors, principals, teachers and secretaries within the Ministry of Public Education were utterly appreciated.

\section{RESUMEN}

Conocimiento sobre cáncer de cérvix entre colegiales de San Carlos, Costa Rica. En Costa Rica, el cáncer de cérvix es el segundo tipo de cáncer femenino más común, a pesar de la accesibilidad del Papanicolaou gracias al sistema de salud universal. No se ha evaluado el nivel de conocimiento de la población adolescente sobre el cáncer de cérvix, aunque este grupo es el más expuesto a los factores de riesgo. Este estudio investigó cuánto sabe el adolescente sobre métodos de prevención, riesgo de infección, manifestaciones clínicas y servicios médicos. En total, 533 estudiantes de séptimo a doceavo año de cinco colegios públicos de la zona rural de San Carlos participaron en esta investigación durante marzo y abril 2012. Se observó que los estudiantes carecen de información, ya que solamente el 30.8\% sabían qué es el cáncer de cérvix. Nuestros resultados indican que es importante incluir el cáncer de cérvix en los programas de educación sexual del sistema de educación pública de Costa Rica, para educar a la población en riesgo acerca de los métodos de prevención, desarrollo de la infección y servicios médicos.

Palabras clave: adolescentes, cáncer de cérvix, Costa Rica, educación sexual, Papanicolaou. 


\section{REFERENCES}

Aguado, T., Beauvais, O., Byrne, S., \& Gacic-Dobo, M. (2010). Human papillomavirus and related cancers: Costa Rica. World Health Organization. Retrieved from http://apps.who.int/hpvcentre/statistics/dynamic/ico/country_pdf/CRI.pdf?CFID $=4005139 \&$ CFT OKEN $=50211239$

American Cancer Society. (2011). Cervical cancer: Prevention and early detection. Retrieved from http:// www.uptodate.com/contents/screening-for-cervicalcancer-rationale-and-recommendations

Feldman, S., Sirovich, B. E., \& Goodman, A. (2011). Screening for Cervical Cancer: Rationale and recommendations. Retrieved from http://www.uptodate. $\mathrm{com} /$ contents /screening-for-cervical-cancer-rationale-and-recommendations

Francis, S. A., Battle-Fisher, M., Hipple, L., Liverpool, J., Mofammere, N., Mosavel. M., \& Soogun, S. (2011). A qualitative analysis of South African women's knowledge, attitudes and beliefs about HPV and cervical cancer prevention, vaccine awareness and acceptance, and maternal-child communication about sexual health. Vaccine, 29(47), 8760-8765.

Instituto Nacional de Estadística y Censos [INEC]. (2011). Población total por zona y sexo, según provincia, canton $y$ distrito. Retrieved from http://www.inec. go.cr/Web/Home/GeneradorPagina.aspx

Kivistik, A., Lang, K., Baili, P., Antitila, A., \& Veerus, P. (2011). Women's knowledge about cervical cancer risk factors, screening, and reasons for non-participation in cervical cancer screening programme in Estonia. BMC Women's Health, 11, 43.

Logan, L. \& Mcifatrick, S. (2011). Exploring women's knowledge, experiences and perceptions of cervical cancer screening in an area of social deprivation. European Journal of Cancer Care, 20(6), 720-727.

Maine, D., Hurlburt, S., \& Greeson, D. (2011). Cervical cancer prevention in the 21 st century: Cost is not the only issue. American Journal of Public Health, 101(9), 1549-1555.

Maree, J. E., Wright, S. C., \& Makua, T. P. (2011). Men's lack of knowledge adds to the cervical cancer burden in South Africa. European Journal of Cancer Care, 20(5), 662-668.

Nwankwo, K. C., Aniebue, U. U., Aquwa, E. N., Anarado, A. N., \& Aqunwah, E. (2011). Knowledge attitudes and practices of cervical cancer screening among urban and rural Nigerian women: A call for education and mass screening. European Journal of Cancer Care, 20(3), 362-367.

Picado, K. (2007). Primera encuesta nacional de juventud, Costa Rica. Fondo de Población de las Naciones Unidas. Retrieved from http://www.unfpa.or.cr/component/content $/ 225$ ?task $=$ view

RHO Cervical Cancer. (2009). About cervical cancer. Retrieved from http://www.rho.org/about-cervicalcancer-quickfacts.htm

Sokal, R. R. \& Rohlf, F. J. (1995). Biometry:The principles and practice of statistics in biological research. New York, NY: W. H. Freeman and Co.

Souza, C. (2011). Media screen time, physical activity and nutritional indicators as risk factors for childhood and adolescent overweight and obesity in Aguas Zarcas, Costa Rica. Semester research project. Field Research in the Environment, Social Science \& Humanities (Spring 2011). San Pedro de Montes de Oca, Costa Rica: Associated Colleges of the Midwest.

Statpoint Technologies, Inc. (2011). Statgraphics Centurion [computer software]. Available from http://www. statgraphics.com

Tse-Chuan, Y., Matthews, S. A., \& Hillemeier, M. M. (2011). Effect of health care system distrust on breast and cervical cancer screening in Philadelphia, Pennsylvania. American Journal of Public Health, 101(7), 1297-1305. 